\title{
INTENSITY MEASUREMENTS IN THE HELIUM SPECTRUM
}

\author{
By Clarence Hodges and W. C. Michels
}

Abstract

The absolute and relative intensities of thirteen lines of the helium spectrum, extending through the visible region, have been measured by a modification of the method developed by Ornstein and Dorgelo. The change of the method has consisted in comparing each line directly with the known emission from a tungsten filament, operated under constant conditions. The results for a discharge in a capillary tube, with pressures from 1.92 to $34.3 \mathrm{~mm}$ show that the absolute intensities increase rapidly to a maximum for pressures in the neighborhood of 2 to $4 \mathrm{~mm}$, below which they tend toward zero. The relative intensities of the singlet system are favored by lowered pressures, and the higher members of the triplet system are likewise favored over the lower members, while the relative intensities within the singlet series show little effect of pressure.

$T$

$\mathrm{HE}$ interesting regularities which have been shown in the intensity relationships of multiplets ${ }^{1}$ and the apparent importance of pressure conditions in the excitation of stellar spectra ${ }^{2}$ seem to make a general study of the effect of pressure on line spectra desirable. The method developed by Ornstein and Dorgelo, ${ }^{3}$ although its use had previously been limited largely to multiplet work, seemed to hold possibilities of extension over larger regions of wave-length, and to studies of this type.

The method, as originally developed, consists of photographing the spectrum through a series of known reducers, and thus obtaining the densityexposure curves for the lines. Over the regions used for multiplet studies, these curves were found to have a constant separation, as they followed very closely the Swartzschild law:

$$
D=\gamma \log \left(I t^{p}\right)+D_{0}
$$

The shift of these curves along the exposure axis to bring them into coincidence made possible a determination of the photographic ratios of intensities. A correction for the sensitivity ratios of the plates, determined by similar photographs taken with a calibrated continuous source, gave the true relative intensities.

When we attempted to extend this method over the range covered in this study (3819-5876A), however, we found that $\gamma$ varied between wide limits with change of wave-length, and we have modified the method by comparing each line directly with the continuous spectrum at the same wave-length, taken with identical exposure time, and on a film from the same box as those used for the line spectrum.

\footnotetext{
1 Ornstein, Proc. Phys. Soc. London 37, 334-347 (1925).

2 Bowen, Astrophys. J. 47, 1-15 (1928).

3 Dorgelo, Phys. Zeits. 26, 1-39 (1925).
} 


\section{Apparatus and Method}

The source used for the helium spectrum consisted of a capillary discharge tube, having an inside diameter of $4 \mathrm{~mm}$ and a length of $10 \mathrm{~cm}$, with hollow aluminum electrodes. The tube was operated at a uniform 50 cycle current of $40 \mathrm{ma}$, and at the following voltages:

$\begin{array}{lrrrrrr}\text { Pressure in } \mathrm{mm} \mathrm{Hg} & 15.5 & 8.6 & 4.7 & 3.4 & 2.7 & 2.58 \\ \text { Voltage across tube } & 540 & 526 & 505 & 500 & 527 & 620\end{array}$

The helium used was purified by immersion in a charcoal, liquid-air trap for about 72 hours, then by circulation between two traps, one containing copper and copper-oxide at $300^{\circ}$ to $400^{\circ} \mathrm{C}$ and the other containing charcoal at liquid-air temperature. The helium treated in this way showed no signs of impurities in its spectrum, except at the lowest pressure at which we worked $(1.92 \mathrm{~mm})$, where a few weak, unidentified lines appeared.

For photographing the spectra a replica concave grating of 1 meter focal length was used, in a Rowland mounting. Five horizontal reducers, constructed of Eastman neutral photographic filters, and transmitting approximately $100,45,20,12$ and 6 percent of the incident light, were mounted on the tangent to the focal circle at the plate, so as to cast a sharp horizontal image at the plate, in accordance with the astigmatism of the mounting. These reducers were calibrated in place by use of a vacuum thermocouple mounted at the camera to measure the transmitted energy at each wavelength.

The continuous comparison source was furnished by a tungsten ribbon filament, 2 by $35 \mathrm{~mm}$, operated at 16 amperes. The temperature under these conditions was measured by Dr. C. H. Prescott ${ }^{4}$ at the beginning and end of the work and was found to hold constant at $2014^{\circ} \mathrm{K}$. From the known emissivity of tungsten, ${ }^{5}$ relative values of the energy in various wave-lengths were calculated. For the weaker helium lines, where longer exposure times were necessary, the intensity of the continuous source was reduced throughout by narrowing the slit. No slit widths of less than $0.3 \mathrm{~mm}$ were used, however, in order that error due to diffraction might be avoided. The normal slit width was $1.5 \mathrm{~mm}$.

The photographs thus obtained on Eastman panchromatic films, showing five spectra, of known relative intensities, side by side, were developed simultaneously in a tank arranged for constant stirring of the developer. The developer was elon-hydroquinone in standard Eastman proportions, and the best time of development was found to be six minutes, at room temperature. All subsequent operations of fixing and washing were carried out simultaneously for the two films.

The densities were determined by measurement, by a vacuum thermocouple, of the light transmitted through the exposed and clear films. Except in a very few cases, the Swartzschild formula was found to hold within three to five percent. Direct comparison with the continuous spectrum was used

- Prescott and Hincke, Phys. Rev. 31, 130-134 (1928).

Forsythe and Worthing, Astrophys. J. 61, 146 (1925). 
for all lines except for 3889 , for which it was impractical to get a continuous source intense enough for comparison, and for the lines of the singlet sharp series, which were too faint for direct comparison. In these cases, the curves were compared with those of closely neighboring lines, and correction was made for sensitivity of the plate.

Fig. 1 shows a typical set of density-intensity curves illustrating both types of determination. The ordinates of density are the logarithms, to the base of ten, of the galvanometer deflection for the clear film divided by the deflection for the portion under consideration, while the abscissas are logarithms of the incident intensity through the various reducers. The horizontal distance between the curves for the continuous and helium films, then, gives the logarithm of the relative intensity for the two sources. The curve for 3889 was shifted to that for 4472 .

\section{Absolute Intensities}

Fig. 2 shows the results obtained for the absolute intensities of the thirteen lines studied (plotted on a logarithmic scale for convenience), the unit of intensity being taken arbitrarily as the light given at $5876 \mathrm{~A}$ by the tungsten filament operating at 16 amperes, and with a slit width of 1.5

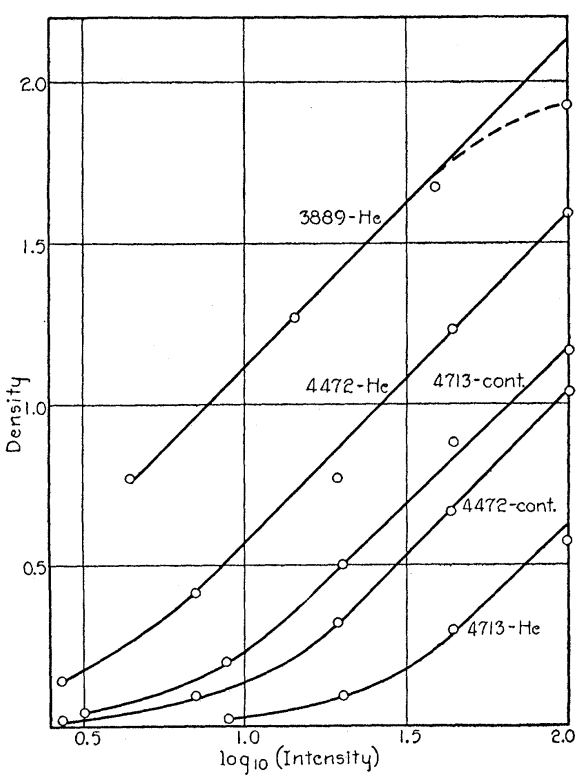

Fig.1. Typical set of density-intensity curves. $\mathrm{mm}$.

Since the error introduced by the irregularities in the photographic film determines the limits of accuracy, we may say that the probable error of any observation is not over five or six percent, for the more intense lines. The curves shown have, in general, been drawn within this limit of the observed points. A few points, notably those for 5876 at 12.1 and $20.0 \mathrm{~mm}$ pressure depart rather widely from the smooth curves. This, it seems, may be accounted for by the fact that this line was very near to the end of our films, where variations in emulsion, errors in development and the like would most probably enter to a large extent. For the six weakest lines, the parts of the density-exposure curves available were below the straight line portion, where best results were obtained, and we should estimate the probable errors on these to run somewhat higher, say eight to ten percent.

The trend of the curves toward a maximum at the lower pressures, with a subsequent decrease, is unmistakable. One of the interesting points in connection with this is the shift of this maximum to lower pressures as we go to higher members of the series, a rule which is violated in none of the cases. 
Dr. I. S. Bowen has suggested that a possible explanation of these observed intensity variations may be found in the observation of Dymond ${ }^{6}$ that the efficiency of excitation of a given initial state is greatest when the energy of the exciting electron is only slightly greater than that needed to excite that state. Consequently a given state with energy $V_{1}$ will be excited in most cases by electrons which have, at the time of impact, an energy between that necessary for excitation of this state and that of the next higher state, $V_{2}$.

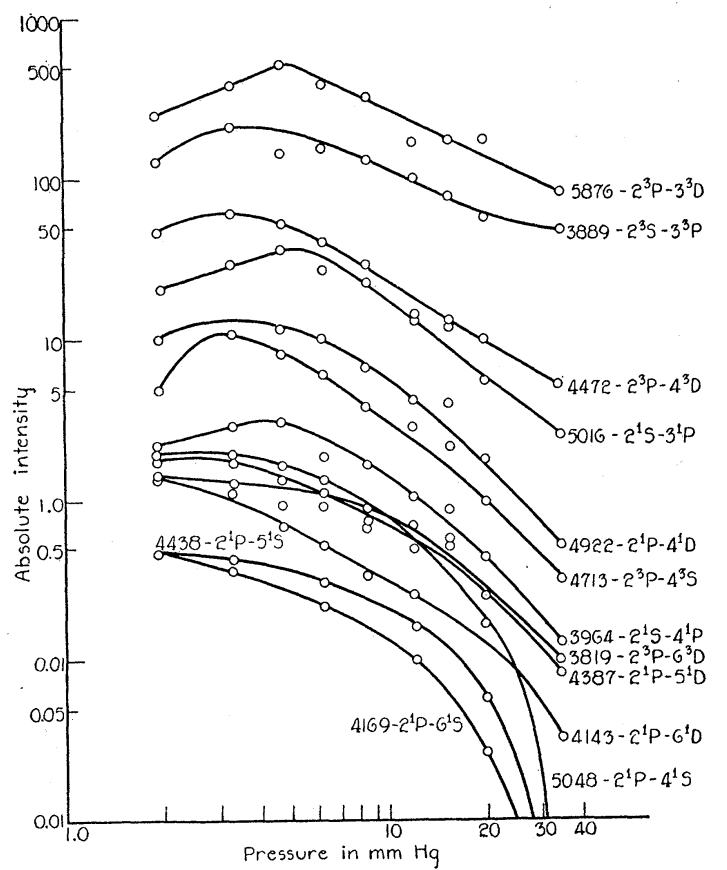

Fig. 2. Absolute intensities of thirteen lines of the helium spectrum.

Thus the probability of excitation of a given state is the same as the probability that an electron will have an impact when its energy is between $V_{1}$ and $V_{2}$. From the well known kinetic theory relations this probability is:

$$
e^{-V_{1} / g y}-e^{-V_{2} / g y}
$$

where $g$ is the potential gradient in the tube and $y$ is the electron mean free path.

Applications of this formula to the experimental data, while they do not agree quantitatively, do give the general type of curve obtained. The relative positions of the maxima, at least, are approximately correctly placed, although the slopes of the curves are much greater than for the experimental results.

Any exact solution of the mechanism of the variations, it seems, will require a greater knowledge of the variations caused by each factor: electron

${ }^{6}$ Dymond, Proc. Roy. Soc. A107, 291-309 (1925). 
velocities, pressure, efficiency of impact and collisions of the second kind. With these objectives in mind, a program of work will be started in an attempt to throw more light on the phenomena.

If the sum of the intensities for all observed lines be taken, it is found that this follows a curve very similar to that for 5876 , the maximum occurring at four millimeters, the point at which the resistance of the tube reaches a minimum of $12300 \mathrm{ohms}$, for the current used.

\section{RELATIVE INTENSITIES}

In Table I the values of the intensities of the various lines relative to 5876 and relative to the lowest observed member of the series are shown. While the regularities apparent in the absolute intensities are not nearly so marked in these values, certain general conclusions may be drawn:

(1) Within the pressure range in which we worked, decrease of pressure favors the singlet series with respect to the triplets.

(2) The higher members of the triplet series are decidedly favored by decrease of pressure, while the relative intensities within a given series of the singlet system shows a much smaller increase, except at the lowest pressure.

TABLE I. Relative intensities of helium lines.

\begin{tabular}{|c|c|c|c|c|c|c|c|c|c|c|}
\hline \multicolumn{2}{|c|}{ Pressure in $\mathrm{mm} \mathrm{Hg}$} & 34.3 & 20.0 & 15.5 & $12.1^{*}$ & 8.6 & 6.3 & 4.7 & 3.3 & 1.92 \\
\hline Wave-length & Notation & \multicolumn{9}{|c|}{ Intensity Relative to 5876} \\
\hline $\begin{array}{l}5876 \mathrm{~A} \\
4472 \\
3819\end{array}$ & $\begin{array}{l}2^{3} P-3^{3} D \\
2^{3} P=4^{3} D \\
2^{3} P=6^{3} D\end{array}$ & $\begin{array}{l}100 \\
\quad 6.20 \\
0.105\end{array}$ & $\begin{array}{c}100 \\
5.89 \\
0.140\end{array}$ & $\begin{array}{c}100 \\
\quad 7.52 \\
0.326\end{array}$ & $\begin{array}{l}100 \\
\quad 8.48 \\
0.388\end{array}$ & $\begin{array}{l}100 \\
\quad 9.2 \\
0.280\end{array}$ & $\begin{array}{l}100 \\
10.6 \\
0.240\end{array}$ & $\begin{array}{l}100 \\
10.4 \\
0.324\end{array}$ & $\begin{array}{c}100 \\
15.8 \\
0.334\end{array}$ & $\begin{array}{l}100 \\
18.8 \\
0.573\end{array}$ \\
\hline 3889 & $2^{3} S-3^{3} P$ & 57.8 & 32.0 & 45.2 & 58.5 & 40.8 & 40.0 & 28.4 & 54.0 & 51.0 \\
\hline 4713 & $2^{3} P-4^{3} S$ & 0.380 & 0.556 & 1.24 & 1.70 & 1.23 & 1.56 & 1.58 & 2.84 & 1.94 \\
\hline 5016 & $2^{1} S-3^{1} P$ & $(100)^{3.06}$ & $(100)^{3.18}$ & $(100)^{6.84}$ & $(100)^{7.95}$ & $(100)^{6.96}$ & $(100)^{6.93}$ & $(100)^{7.08}$ & $(100)^{7.50}$ & ${ }^{8.23}$ \\
\hline 3964 & $2^{1} S-4^{1} P$ & $\begin{array}{r}0.155 \\
(5.05)\end{array}$ & $\begin{array}{l}0.245 \\
(7.7)\end{array}$ & $\begin{array}{l}0.558 \\
(8.2)\end{array}$ & $\begin{array}{c}0.504 \\
(6.3)\end{array}$ & $\begin{array}{l}0.528 \\
(7.6)\end{array}$ & $\begin{array}{l}0.487 \\
(7.0)\end{array}$ & $\begin{array}{l}0.605 \\
(8.6)\end{array}$ & $\begin{array}{l}0.739 \\
(9.8)\end{array}$ & $\begin{array}{c}0.885 \\
(10.7)\end{array}$ \\
\hline 5048 & $2^{1} P-4^{1} S$ & - & ${ }_{(100)}^{0.110}$ & - & $\begin{array}{l}0.289 \\
(100)\end{array}$ & - & ${ }_{(100)}^{0.346}$ & 一 & ${ }_{(100)}^{0.492}$ & ${ }_{(100)}^{0.768}$ \\
\hline 4438 & $2^{1} P-5^{1} S$ & - & $\begin{array}{c}0.033 \\
(30.3)\end{array}$ & - & $\begin{array}{c}0.099 \\
(34.0)\end{array}$ & 一 & $\begin{array}{c}0.078 \\
(22.5)\end{array}$ & 一 & $\begin{array}{c}0.111 \\
(22.6)\end{array}$ & $\begin{array}{l}0.174 \\
(22.7)\end{array}$ \\
\hline 4169 & ${ }^{1} P-6^{1} S$ & - & $\begin{array}{c}0.015 \\
(13.8)\end{array}$ & 一 & $\begin{array}{c}0.063 \\
(21.8)\end{array}$ & - & $\begin{array}{c}0.058 \\
(16.0)\end{array}$ & - & $\begin{array}{c}0.094 \\
(19.1)\end{array}$ & $\begin{array}{l}0.183 \\
(22.8)\end{array}$ \\
\hline 4922 & $2^{1} P-4^{1} D$ & ${ }_{(100)}^{0.620}$ & $(100)^{1.01}$ & ${ }_{(100)}^{2.28}$ & ${ }^{2.45}$ & ${ }^{2.06}$ & $(100)^{2.59}$ & $(100)^{2.26}$ & $(100)^{3.33}$ & ${ }_{(100)^{4.03}}$ \\
\hline 4387 & $2^{1} P-5^{1} D$ & $\begin{array}{c}0.010 \\
(16.1)\end{array}$ & $\begin{array}{l}0.095 \\
(9.4)\end{array}$ & $\begin{array}{c}0.287 \\
(12.6)\end{array}$ & $\begin{array}{c}0.394 \\
(16.1)\end{array}$ & $\begin{array}{c}0.230 \\
(11.0)\end{array}$ & $\begin{array}{c}0.284 \\
(11.0)\end{array}$ & $\begin{array}{c}0.265 \\
(11.3)\end{array}$ & $\begin{array}{c}0.450 \\
(13.5)\end{array}$ & $\begin{array}{c}0.695 \\
(17.2)\end{array}$ \\
\hline 4143 & ${ }^{1} P-6^{1} D$ & $\begin{array}{l}0.004 \\
(6.45)\end{array}$ & $\begin{array}{l}0.07 \\
(6.93)\end{array}$ & $\begin{array}{l}0.143 \\
(6.28)\end{array}$ & $\begin{array}{l}0.195 \\
(7.95)\end{array}$ & $\begin{array}{l}0.165 \\
(8.0)\end{array}$ & $\begin{array}{l}0.176 \\
(6.8)\end{array}$ & $\begin{array}{l}0.209 \\
(9.2)\end{array}$ & $\begin{array}{l}0.287 \\
(8.8)\end{array}$ & $\begin{array}{l}0.562 \\
(13.9)\end{array}$ \\
\hline
\end{tabular}

* Possibly all this column is high, because of probable error in 5876 .

The authors wish to express their indebtedness to Dr. R. A. Millikan and to Dr. I. S. Bowen for their interest in the work and the help they have rendered us.

Norman BRIDGE Laboratory,

California Institute of Technology.

August 16, 1928. 